\title{
Assessment of dimensions of pneumatisation of the anterior clinoid process in middle Anatolian population by computed tomography
}

\author{
V. Sabanciogullari ${ }^{1}$, Y. Tastemur ${ }^{1}$, I. Salk ${ }^{2}$, G. Dogruyol ${ }^{1}$, M. Cimen ${ }^{1}$ \\ ${ }^{1}$ Department of Anatomy, Cumhuriyet University Faculty of Medicine, Sivas, Turkey \\ ${ }^{2}$ Department of Radiology, Cumhuriyet University Faculty of Medicine, Sivas, Turkey
}

[Received: 21 September 2017; Accepted: 25 December 2017]

Background: The anterior clinoid process $(A C P)$ is usually removed during surgical procedures of the cellar region. The ACP may be different length and width in people; it may be also pneumatic. Therefore, we aimed to determine dimensions and rates of pneumatisation of the ACP in the large study group with clinically importance.

Materials and methods: One thousand and thirty-one (592 female, 439 male) cranial computed tomography (CT) of the middle Anatolian population was used in this study. The length and basal width of the ACP were measured on the cranial CT. Also; incidence and degree of ACP pneumatisation were identified.

Results: The width of the right and left ACPs in females were $10.80 \pm 2.27 \mathrm{~mm}$ and $10.53 \pm 2.07 \mathrm{~mm}$, respectively. The width of the right and left ACPs in males were $11.08 \pm 2.39 \mathrm{~mm}$ and $10.98 \pm 2.35 \mathrm{~mm}$, respectively. The length of the right and left ACPs in females were $8.32 \pm 2.40 \mathrm{~mm}$ and $8.34 \pm 2.35 \mathrm{~mm}$, respectively. The length of the right and left ACPs in males were $8.87 \pm 2.62 \mathrm{~mm}$ and $8.93 \pm 2.64 \mathrm{~mm}$, respectively. There was statistically significant difference between males and females in ACP dimensions, except for the width of the right ACP. Pneumatisation of the ACP was observed on the right side in 46 (9.3\%) cases, on the left side in 53 (10.6\%) cases, and bilaterally in 32 (6.5\%) cases. Incidence of pneumatisation of the ACP was decreased in the age group of 1 month to 20 years. While the incidence of bilateral pneumatisation of the ACP was higher in individuals aged 21-40.

Conclusions: Radiologically recognising pneumatisation and anatomical variations of the ACP may be helpful in decreasing the incidence of surgical complications during anterior clinoidectomy. (Folia Morphol 2018; 77, 3: 558-563)

Key words: anterior clinoid process, pneumatisation, computed tomography

\section{INTRODUCTION}

The medial end of the back edge of lesser wing of sphenoid bone (ala minor) is highly long and called anterior clinoid process (ACP). The size of this process may vary from person to person and can also be pneumatised $[9,10,13]$.

Anterior clinoidectomy is preferred in order to provide a clear field of view in the surgical therapies

Address for correspondence: Associate Prof. Dr. V. Sabanciogullari, Department of Anatomy, Cumhuriyet University School of Medicine, 58140 Sivas, Turkey, tel: +90346 2191010, fax: +90 346 2191284, e-mail: vsabanci@yahoo.com.tr 
of the lesions such as cavernous sinus meningiomas, paraclinoid aneurisms and skull base tumours, and to provide a finest intervention to pathologies. However, after removing of clinoid process, various complications may occur. The most commonly encountered complications include aneurysm ruptures, visual impairment, oculomotor nerve palsy and internal carotid artery injuries.

Rhinorrhoea, in particular, is more likely to occur, which is the case of the pneumatisation of anterior clinoids. The incidence of rhinorrhoea occurrence following the anterior clinoidectomy is reported to be $2.7-7 \%$. Several studies suggest that the pneumatisation of anterior clinoids varies from $4 \%$ to $29.3 \%$ [7-9]. However, the studies in Turkey examining the ACP dimensions and the pneumatisation levels are limited $[1,3,5]$.

Thus, we aimed to evaluate the dimensions of ACP and the levels of pneumatisation and to determine whether these parameters could affect the success to the operation in procedures focused especially on skull base in a large study group.

\section{MATERIALS AND METHODS}

This retrospective study was approved by our University's Human Research Ethics Committee and conducted according to its standards. Picture archiving and communication system (PACS) of our university hospital was screened for cranial computed tomography (CT) scans of patients referred from the various clinical departments.

Between September 2015 and October 2016, multidetector $\mathrm{CT}$ scans obtained in 1150 consecutive patients (592 females and 439 males) were studied. One hundred nineteen patients with paraclinoid, paranasal sinus or hypophyseal disorders were excluded from the study group.

The right and left ACP length, base width, and the most distal tips were measured on the axial CT images. To determine the basal width of the ACP, the distance between the outer edge of the lesser wing and the medial side of the optic canal were measured (M1, M3). To determine the length of the ACP, the distance between the apex of ACP and the line used as the base width were measured (M2, M4). It was also measured the distance between the apexes of the clinoids (M5) (Fig. 1) [7, 8]. In addition, the presences of clinoid pneumatisation were evaluated (Fig. 2).

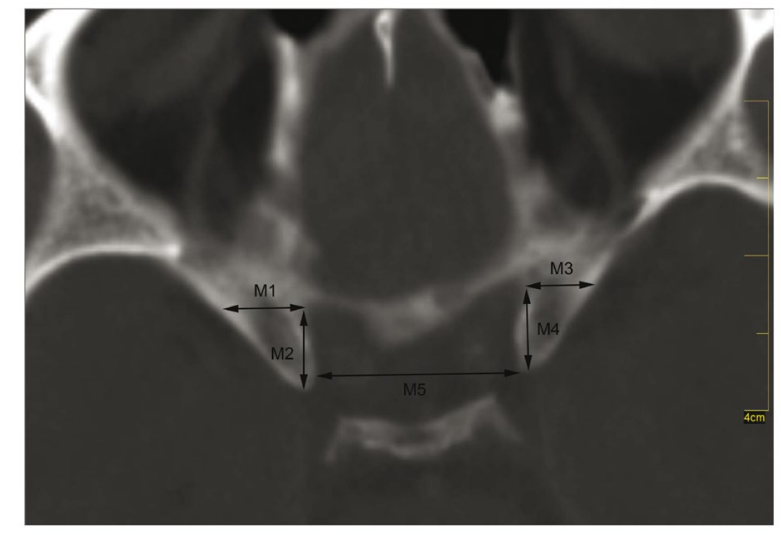

Figure 1. Anterior clinoid process (ACP); $M 1$ - basal width of the right $\mathrm{ACP} ; \mathrm{M} 2$ - length of the right $\mathrm{ACP} ; \mathrm{M} 3$ - basal width of the left ACP; M4 - length of the left ACP; M5 - distance between the anterior clinoid tips. Length of the ACP (M2, M4): Anterior clinoid tip to the medial margin of the optic canal. Basal width of the ACP (M1, M3): Medial margin of the optic canal to the lateral edge of the anterior clinoid process.

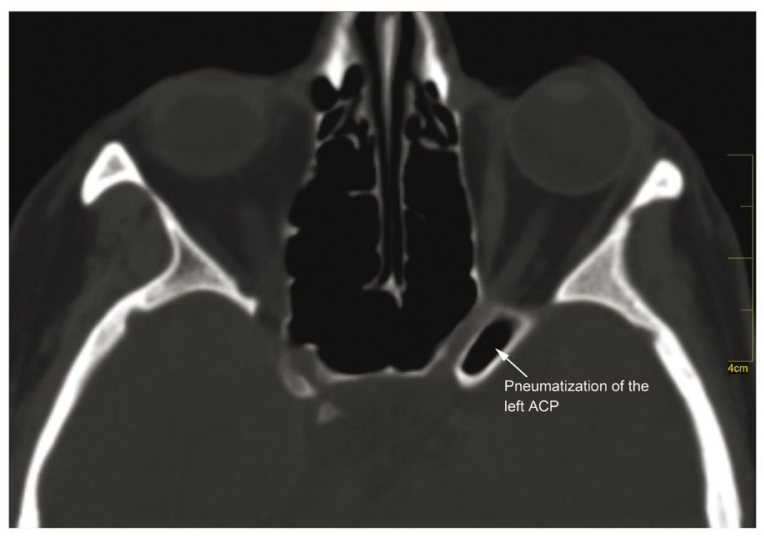

Figure 2. Pneumatisation of the left anterior clinoid process (ACP).

All CT examinations were performed with 128-slice multidetector CT scanner with standard protocols (Aquilion, Toshiba Medical Systems, Tokyo, Japan); they were generally performed for the differential diagnosis of headache. CT examinations were performed with and without contrast medium enhancement, in axial sections with $0.5-\mathrm{mm}$ collimation using $120 \mathrm{kV}, 210 \mathrm{mAS}$ values.

Image measurements were performed on a workstation (Aquarius Intuition Edition ver. 4.4.6, TeraRecon Inc., San Mateo, CA, USA) as appropriate by one investigator (I.S.) who was blind to the clinical data. Intraobserver variability, determined for measurements as kappa coefficient. ranged from 0.80 to 0.89 . 


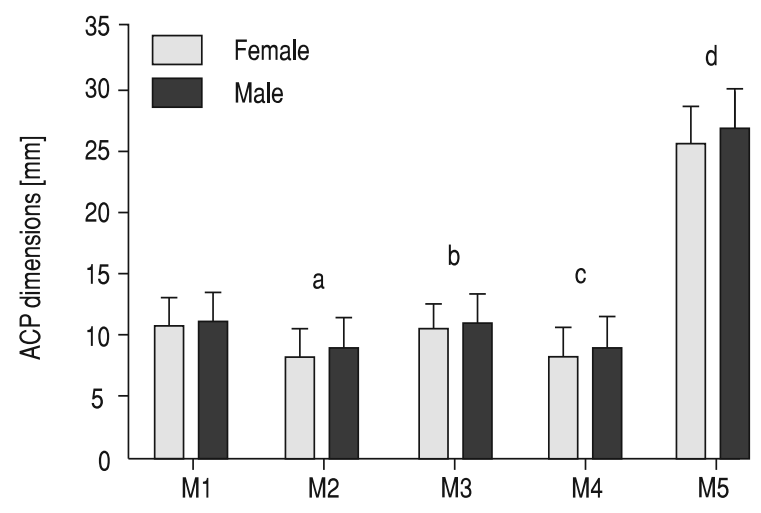

Figure 3. The comparison of anterior clinoid process (ACP) dimensions by gender. Data are expressed as mean \pm standard deviation; ${ }^{a, b}, c, d p<0.05$ vs. M2, M3, M4 and M5 groups. M1 - basal width of the right ACP; $M 2$ - length of the right $A C P ; M 3$ - basal width of the left ACP; M4 — length of the left ACP; M5 — the distance between the apex of the ACP.

\section{Statistical analysis}

The patient data and statistical analysis were evaluated by using the SPSS 15.0 for Windows Statistical Programme Statistical analyses were performed by using Student's t-test, one-way ANOVA, $\chi^{2}$ and correlations. A $p$ value $<0.05$ was considered as statistically significant.

\section{RESULTS}

One thousand and thirty-one (592 female, 439 male) cranial CT of the middle Anatolian population was included in this study. The mean age of the study group was $46.33 \pm 20.69$ ( 1 month to 90 years). The mean age of the patients was $46.33 \pm 20.69$ (0-90 years).

The ACP was both wider and longer in males then females. This difference was also statistically significant, except for basal width of the right ACP $(p<0.05)$. Moreover, the distance between the apex of ACP was also higher in men $(p<0.05)$ (Fig. 3 ).

The ACP pneumatisation in individuals aged less than 20 years was decreased, while it was increased in 21-40 years old individuals. In all the age groups, the left-side clinoid process was observed to be more pneumatised. Bilateral pneumatisation was seen in all age groups; especially its percentage was increased in the age group of 21-40 years old (Fig. 4).

The percentage of ACP pneumatisation of both the right and left sides, and bilaterally were higher in males then females (Fig. 5).

Figure 6 shows the ACP dimensions of presence of pneumatisation by age groups. In the group of less than 20 years, there was no statistically significance

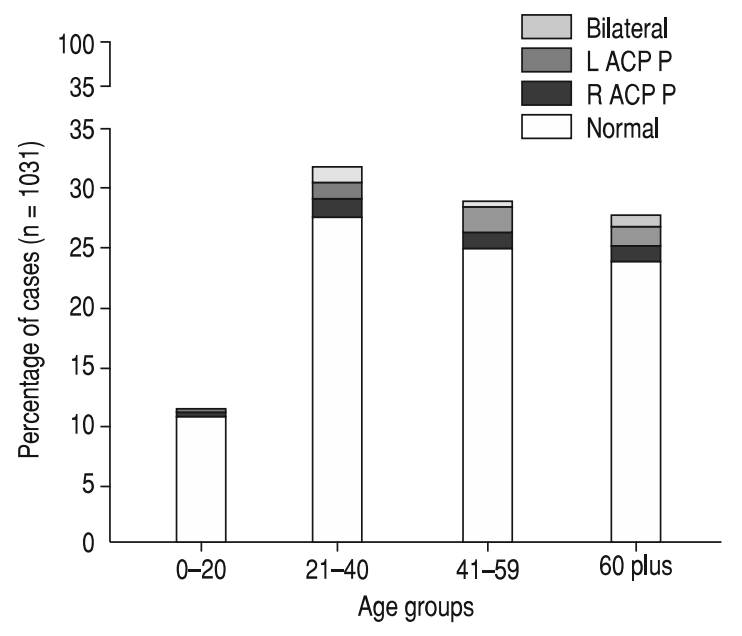

Figure 4. The percentage of anterior clinoid process (ACP) pneumatisation by age groups; L ACP P — left ACP pneumatisation; $\mathrm{R} A C P \mathrm{P}$ - right ACP pneumatisation.

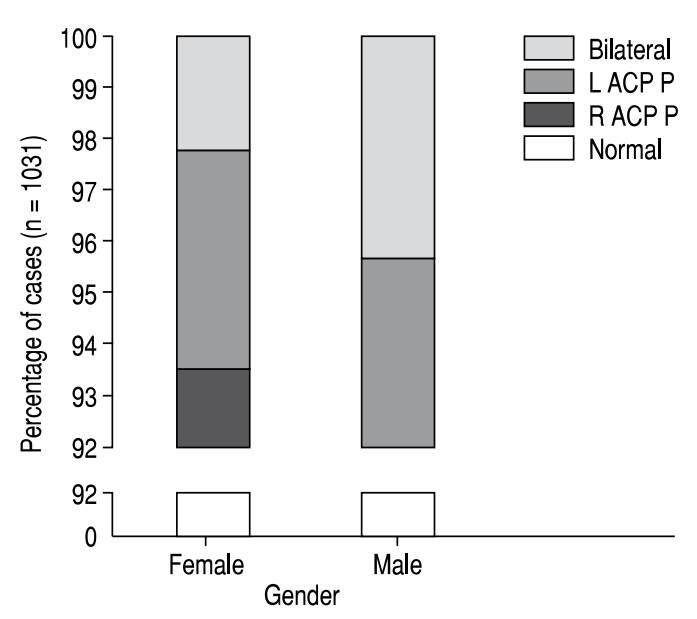

Figure 5. The percentage of anterior clinoid process (ACP) pneumatisation by gender; L ACP P — left ACP pneumatisation; $\mathrm{R}$ ACPP — right ACP pneumatisation.

difference between presence of pneumatisation and normal cases ( $p>0.05)$. Both right and left anterior clinoid basal widths (M1 and M3) of the groups of 21-40 and 41-59 were significantly higher in the group with the presence of pneumatisation than in normal group $(p<0.05)$. Moreover, in the group of 21-40, the distance between the apexes of ACP was significantly higher among the group with the presence of pneumatisation than in normal group $(p<0.05)$ (Fig. 6).

Figure 7 shows correlations between the presence of pneumatisation and ACP dimensions. There is only mild-to-moderate significant correlation between basal width of the right $A C P$ and length of the right $A C P$ 



Figure 6. The anterior clinoid process (ACP) dimensions of presence of pneumatisation by age groups. Data are expressed as mean \pm standard deviation; A. 1 month-20 years old; B. 21-40 years old; a, bp $<0.05$ vs. M1, M3 and M5 groups; C. 41-59 years old; ${ }^{a}$, bp $<0.05$ vs. M1 and M3 groups; D. 60 plus; M1 — basal width of the right ACP; M2 - length of the right ACP; M3 - basal width of the left ACP; M4 - length of the left ACP; M5 — the distance between the apexes of the ACP; $A C P P(+)$ - the presence of pneumatisation.

in unilateral pneumatisation on the right side $(r=0.39$, $p<0.05)$. No meaningful relationship between other parameters was present.

\section{DISCUSSION}

We found the pneumatisation of ACP to be higher in those aged 21 to 40 years. Taking into account all age groups, the rate of ACP pneumatisation was $12.70 \%$.

Mikami et al. [9] determined the rate of ACP pneumatisation to be $9.2 \%$, and reported that $81.8 \%$ of the pneumatisation resulted from sphenoidal sinus.

Abuzayed et al. [1] reported ACP pneumatisation in $9.6 \%$ of the patients involved in their study. In addition, they reported that the rate of left-side ACP pneumatisation was $2.1 \%$, right side was $1.7 \%$ and bilateral pneumatisation was $5.7 \%$.

Arslan et al. [3] noted the ACP pneumatisation as $6 \%$; Bolger et al. [4] reported it as $13.3 \%$.

Sapci et al. [11] found the ACP pneumatisation to be $11 \%$ in their study including the analyses of paranasal sinus CT images of 100 patients. They also stated that $23 \%$ of the ACP pneumatisation cases were accompanied by nerve rupture.

Sirikci et al. [12] reported that there was a statistically significant relationship between the ACP pneumatisation and protrusion of optic nerve to sphenoidal sinus.

In our study, right-side ACP pneumatisation was found to be $4.46 \%$, left-side ACP pneumatisation $5.14 \%$, and bilateral pneumatisation $3.10 \%$.

Lee et al. [8] measured the basal width and length of ACP in 73 skulls belonging to adult Koreans to be $9.63 \mathrm{~mm}$ and $9.18 \mathrm{~mm}$ on average, respectively. In their measurements on 6 male and 5 female cadavers, belonging to adult Koreans, Lee et al. [7] found the average base width of ACP to be $10.82 \mathrm{~mm}$ and the average base length to be $7.61 \mathrm{~mm}$. They measured the base width and length of right-side clinoids as $10.70 \pm 2.11 \mathrm{~mm}$ and $7.65 \pm 1.64 \mathrm{~mm}$, respectively; and the base width and length of left-side clinoids as $10.93 \pm 1.46 \mathrm{~mm}$ and $7.58 \pm 1.35 \mathrm{~mm}$, respectively.

In their study, involving 10 adult cadaver's craniums, Andaluz et al. [2] measured the ACP intradural 

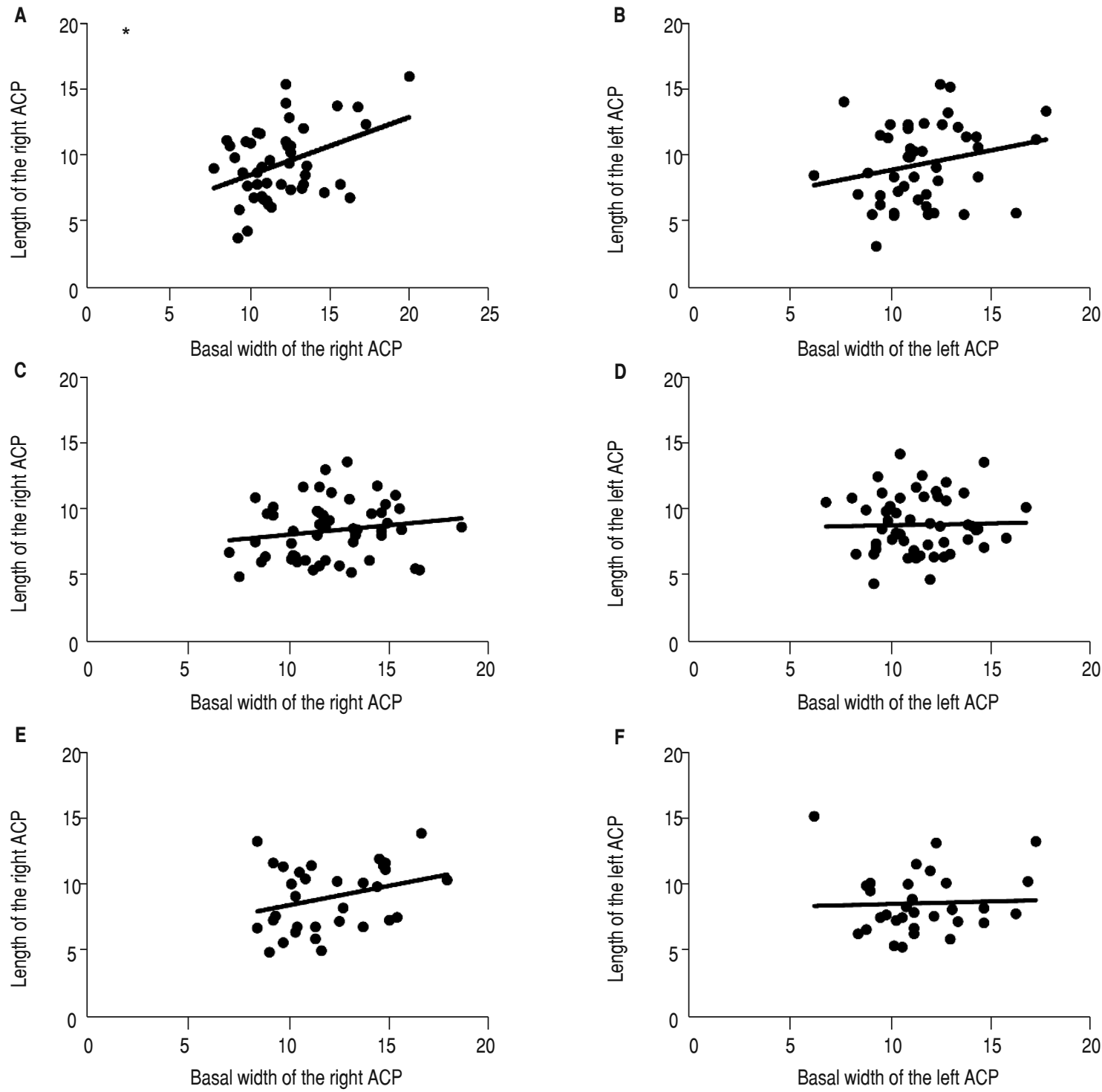

Figure 7. Correlations of the presence of pneumatisation and anterior clinoid process (ACP) dimensions. Data were expressed as mean \pm standard deviation; A, B. Unilateral pneumatisation on the right side; C, D. Unilateral pneumatisation on the left side; E, F. Bilateral pneumatisation; ${ }^{*} p<0.05$.

base width and length as $6.57 \pm 1.68 \mathrm{~mm}$ and $8.67 \pm$ $\pm 2.63 \mathrm{~mm}$, respectively.

Bozkurt and Tağıl [5] measured 36 skull bases and found the ACP base width and length to be $9.63 \mathrm{~mm}$ and $10.05 \mathrm{~mm}$, respectively. Also, they noted that these values were higher in the right side.

Inoue et al. [6] found ACP length as $10.99 \mathrm{~mm}$ on average $(6.5-16.00 \mathrm{~mm})$, base width as $15.2 \mathrm{~mm}$ on average $(12.0-19.5 \mathrm{~mm})$, the distances between the apexes of the clinoids as $22.3 \mathrm{~mm}(18.0-28.0 \mathrm{~mm})$.

In our study, right clinoid base width was increased in both women and men, whereas the clinoid length was increased in the left side. Furthermore, ACP in men was increased both at right and at left com- pared with women. The distance between clinoids was increased in men. We found that the increase in base width increased the presence of pneumatisation, although length had no effect on it $(p<0.05)$.

Some researchers analysed in which ways anterior clinoids were pneumatised, and how significant surrounding soft tissues were affected by pneumatisation. In our study, the dimensions of clinoids as well as the presence and level of pneumatisation were determined, but soft tissues were not analysed. Further studies may reveal how anatomical formations in the parasellar region are affected by the dimensions of clinoids and pneumatisation by using magnetic resonance images in which soft tissues are seen more clearly. 


\section{CONCLUSIONS}

As a result, both the length and the width of ACP are higher in men. The increase in base width also increases the pneumatisation of $\mathrm{ACP}$, and the incidence of bilateral pneumatisation is higher in individuals aged 21 to 40 years. Therefore, taking into account the pneumatisation and dimensions of anterior clinoids might decrease the complications and may increase the success rate of surgical interventions in sellar region especially in patients aged 21 to 40 years.

\section{REFERENCES}

1. Abuzayed B, Tanriover N, Biceroglu H, et al. Pneumatization degree of the anterior clinoid process: a new classification. Neurosurg Rev. 2010; 33(3): 367-73; discussion 374, doi: 10.1007/ s10143-010-0255-8, indexed in Pubmed: 20333429.

2. Andaluz N, Beretta F, Bernucci C, et al. Evidence for the improved exposure of the ophthalmic segment of the internal carotid artery after anterior clinoidectomy: morphometric analysis. Acta Neurochir (Wien). 2006; 148(9): 971-5; discussion 975, doi: 10.1007/s00701-006-0862-x, indexed in Pubmed: 16917665.

3. Arslan $H$, Aydinlioğlu A, Bozkurt $M$, et al. Anatomic variations of the paranasal sinuses: CT examination for endoscopic sinus surgery. Auris Nasus Larynx. 1999; 26(1): 39-48, indexed in Pubmed: 10077255.

4. Bolger WE, Butzin CA, Parsons DS. Paranasal sinus bony anatomic variations and mucosal abnormalities: CT analysis for endoscopic sinus surgery. Laryngoscope. 1991;
101(1 Pt 1): 56-64, doi: 10.1288/00005537-19910100000010, indexed in Pubmed: 1984551.

5. Bozkurt MC, Tağıl SM. Processus clinoideus anterior ve optik strut'un morfometrisi. Ankara Üniversitesi Tıp Fakültesi Mecmuası. 2000; 53(4): 227-230.

6. Inoue T, Rhoton AL, Theele D, et al. Surgical approaches to the cavernous sinus: a microsurgical study. Neurosurgery. 1990; 26(6): 903-932, indexed in Pubmed: 2362670.

7. Lee HW, Park HS, Yoo KS, et al. Measurement of critical structures around paraclinoidal area: a cadaveric morphometric study. J Korean Neurosurg Soc. 2013; 54(1): 14-18, doi: 10.3340/jkns.2013.54.1.14, indexed in Pubmed: 24044074.

8. Lee HY, Chung IH, Choi BY, et al. Anterior clinoid process and optic strut in Koreans. Yonsei Med J. 1997; 38(3): 151-154, doi: 10.3349/ymj.1997.38.3.151, indexed in Pubmed: 9259614.

9. Mikami T, Minamida Y, Koyanagi I, et al. Anatomical variations in pneumatization of the anterior clinoid process. J Neurosurg. 2007; 106(1): 170-174, doi: 10.3171/ jns.2007.106.1.170, indexed in Pubmed: 17236504.

10. Moore KL, Dalley AF. Clinically Oriented Anatomy, 4th Edition. Lippincott Williams \&Wilkins, Philadelphia, New York. 1999: 280-289.

11. Sapçi T, Derin $E$, Almaç $S$, et al. The relationship between the sphenoid and the posterior ethmoid sinuses and the optic nerves in Turkish patients. Rhinology. 2004; 42(1): 30-34, indexed in Pubmed: 15072031.

12. Sirikci A, Bayazit YA, Bayram M, et al. Variations of sphenoid and related structures. Eur Radiol. 2000; 10(5): 844-848, doi: 10.1007/s003300051016, indexed in Pubmed: 10823645.

13. Williams PL, Bannister LM, Berry MM. Gray's anatomy 39th ed. Churchill Livingstone, London. 2005; 467. 